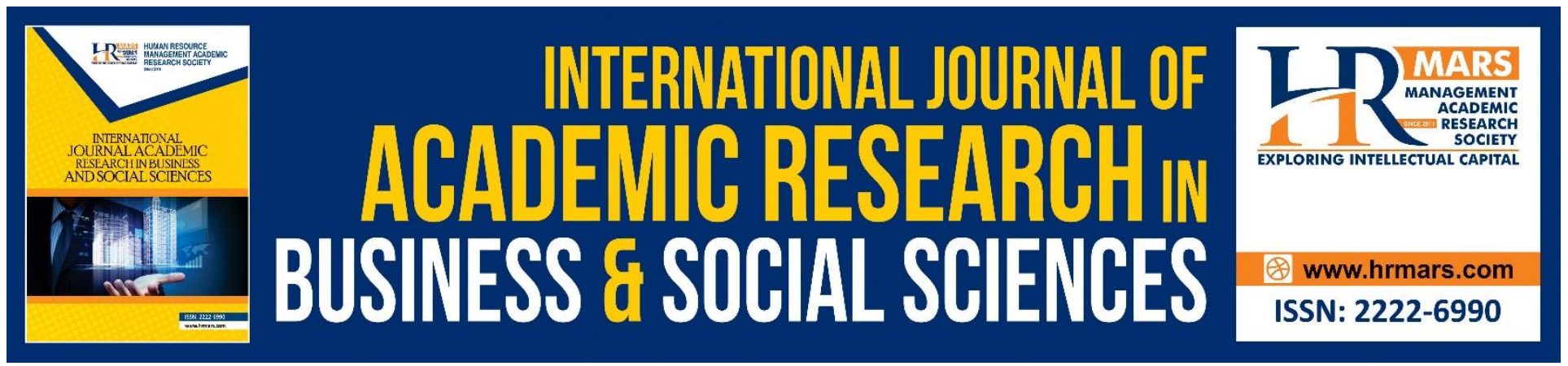

\title{
Cultural Elements that Affect Customer Acceptance towards Global Product Advertisement
}

\author{
Azurin Sani \\ Masila Md Yunus \\ Norlida Kamaluddin
}

To Link this Article: http://dx.doi.org/10.6007/IJARBSS/v8-i11/5564

DOI: $10.6007 /$ IJARBSS/v8-i11/5564

Received: 11 Oct 2018, Revised: 28 Nov 2018, Accepted: 30 Nov 2018

Published Online: 02 Dec 2018

In-Text Citation: (Sani, Yunus, \& Kamaluddin, 2018)

To Cite this Article: Sani, A., Yunus, M. M., \& Kamaluddin, N. (2018). Cultural Elements that Affect Customer Acceptance towards Global Product Advertisement. International Journal of Academic Research in Business and Social Sciences, 8(11), 2008-2016.

\section{Copyright: (C) 2018 The Author(s)}

Published by Human Resource Management Academic Research Society (www.hrmars.com)

This article is published under the Creative Commons Attribution (CC BY 4.0) license. Anyone may reproduce, distribute, translate and create derivative works of this article (for both commercial and non-commercial purposes), subject to full attribution to the original publication and authors. The full terms of this license may be seen

at: http://creativecommons.org/licences/by/4.0/legalcode

Vol. 8, No. 11, 2018, Pg. 2008 - 2016

Full Terms \& Conditions of access and use can be found at http://hrmars.com/index.php/pages/detail/publication-ethics 


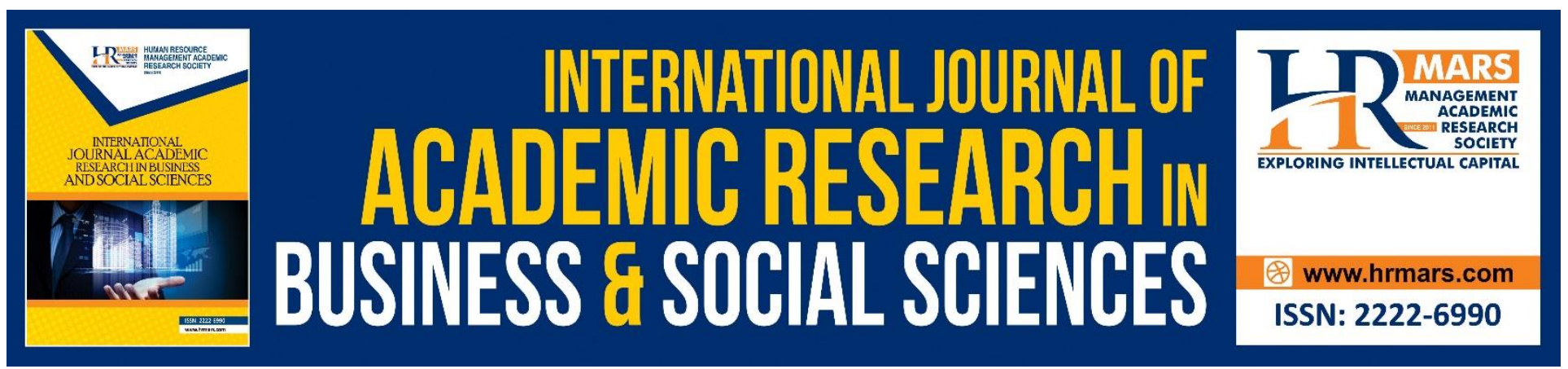

\title{
Cultural Elements that Affect Customer Acceptance towards Global Product Advertisement
}

\author{
Azurin Sani \\ Universiti Teknologi MARA, Malaysia \\ Masila Md Yunus \\ Universiti Teknologi MARA, Malaysia \\ Norlida Kamaluddin (PhD) \\ Universiti Teknologi MARA, Malaysia
}

\begin{abstract}
Advertising has become a powerful driving force as an effective communication medium predominantly utilized to capture worldwide consumers. Conclusively, global advertising is the most visible firms' activity in marketing mix elements which greatly influence by cultures which are known as one of the critical factors that affect economic development, demographic behavior, and general business policies around the world and directly affect how people decipher the message they receive. For this reason, better proficiency of potential customers behold of culture should be acknowledged and exercised by global advertising firm and global merchants. Objective: This paper aimed to examine the effects of the culture elements array in global product advertisements content towards customer acceptance of a global product. Results: Findings show that there is the existence of the significant effects of cultural elements such as religion, language, and cultural norms display in global product advertisement which influences customer attitude towards the global product. Conclusion: Considering the effect of culture blunders that will drive the global firm to hesitate in the targeted market, this research thus suggests global advertising companies and global marketer do the necessary action.
\end{abstract}

Keywords: Cultural Elements, Language, Religion, Norms, Customer Acceptance

\section{INTRODUCTION}

It can't be denied that advertising is essential where it means to generate awareness of products into the public eye (Keller, 2012) and culturally bound. Aware of various cultures in the world may influence the effectiveness of marketing strategy, more global marketers nowadays execute their advertising campaign to suit for many cultures so that it can be positively accepted globally. This is 
because when values of consumers compatible with values reflect in the advertisement, the liking to the brand, ad and company will increase and the ad will become more effective (de Mooij and Hofstede, 2010). Contemporary research has seen many scholars and sociologist carry out culture significant in various marketing and management activities as their research area. However, much study previously highlighted the response of the audience to ads across cultures and lack of research regarding how audience responding to global product promoted in global ads.

Furthermore, Gerritsen, Nickerson \& van Hooft (2010) found that other research was conducted in language capacity as compared to other likely culture elements variables. To date, no studies investigated the effect of religious symbols and cues as a predictor of advertisement process among Malaysian Muslims (Naseri and Tamam, 2012). According to Abdulbaqi and Raji (2012), cultural elements such as language, religion, and cultural norm are the perceived adoptable in Malaysia media which differ to Western held beliefs in ads. In 2009, Malaysian Communications and Multimedia Commission reported that RM14.9 million worth of advertisements was spent in the first half of 2008 signaling that Malaysian has positive attitudes towards global ads. This study thus examines the effects of cultural elements in global advertising and whether it brings significant impact towards consumer acceptance.

Religion: Kotabe and Helsen (2010) defined religion as a belief in supernatural agents. Religion has a crucial role in many communities in the world. This belief has influenced people's buying motives, customs, and practices because religion is perceived as key part of a consumer's life. Religion can affect global marketing strategies (Yalcin and Cimendag, 2012). Naseri and Tamam (2012) considered that Muslims perception conveyed in advertisement messages might differ in contrast with other religion. Additionally, in some countries holiday calendar is structured by religion, many global companies took this as the key event to obtain a gradual rise in product sales where products increasingly commercialized during those events to attract the customer. (Naseri and Tamam, 2012). The author also describes that religious holds notable impact towards consumer attitude of controversial products and response to religious cues or symbols in advertisements. On the other hand, De Run, Butt, Fam and Jong, (2010) analyzed that the assessment of offensive nature of advertisement differ depends on the level of religiosity of viewers. According to De Run et. al., (2010) Malaysian perception of controversial directly rely on the degree of religiosity to some extent consumers differ in terms of the manner product is commercialized that makes ads offensive rather than the nature of the product itself. The author believes that higher religiosity circles easily get offended by the advertisement of haram or controversial products and they tend to accept nudity, sexist image and violence unfavorably than the low religiosity group. These scholars finally conclude that universal application stressed that religion dominates human orientation in relation to life is not appropriate, but religiosity does have an impact towards consumption behavior.

Language: is essential when communicating with worldwide consumer and indeed reflects a culture. Heterogeneity of languages across and within the bounds of national around the world might easily cause wrong interpretation of advertising transcript. Abdulbaqi and Raji (2012) said that consumer deserve to be communicated in their desired manner and language. In their study, language is related to words used in the advertisement. Kotabe and Helsen, (2010) describe translation errors of company's slogan, using words with multiple meanings and mistakes of using idioms or local slang 
are among the factors that unconsciously brings language-related advertising blunder. In study conducted in 5 non-English-speaking countries in Western Europe, Gerritsen et al (2010) found that 40 percent of respondents unable to translate the meaning of English phrases used in product advertisement. Inimitable, language often has strong influence (Schnalke and Mason, 2014) and obviously has significant effect towards advertising activity (Tian and Borges, 2011). According to De Run, Yee and Khalique (2012) language usage literally convey global marketers' images to customers abroad, the handling of the simplest vocabulary, idioms, grammar, cultural references and accent of customers should be taken into care. As a key driver in global advertising, global marketers need to cautiously decide the brand names to adopt market or using subtitles and spoken part in commercial or advertising copy should they intend to induce acceptance of global products from consumers. Nevertheless, still some author argued regarding the strategy of using similar advertising themes, appeals or media for different cultures because some advertisers though believe that worldwide consumer are approachable by likely advertisement concept and language thus questioned whether standardization approach to advertising can be implemented.

Cultural Norms: Norms to some extent provide insight of other culture likely to behave other than allow guidance about how people in given culture should behave and reflect their consumption pattern as well (Nwagbara, 2012). The scholar extends the definition of norms or values by every society has their own sets of norms or values blueprint with the function to steer, educate and converse people into the different roles as a measure to preserve their values. This comprehension, attitude, values, and skills more reflects the culture of a society. In terms of international businesses, cultural norms which derived from value system is salient to market entry and product decisions since norms shape people's viewpoint in given society toward objects and behavioral codes. Despite that, cultural norms are unique from each culture because a norm does not necessarily resistant, yet change might influence culture's attitudes. As Kotabe and Helsen (2010) state that international marketers can leverage local attitudes toward overseas unfamiliar cultures belief in their product positioning and design decisions strategy host country market. Nevertheless, humankind that resistant to change is said that less willing to accepting new products or production processes. In the meanwhile, Abdulbaqi and Raji (2012) explained that culture norms directly affect the way people are living, communicate and interact. Norms are accepted as literal ideology or philosophy of cultural frontier which consists of folkways, taboos, mores, and laws. In research conduct by the author, they found that cultural norms do form product advertisement reception which directs to customer behavior towards the product. As proposed by Naseri and Tamam in 2012, the recognition advertisements for a specific group of people are designated by cultural values and norms. For some global ads to be effective, the degree of excellence of products and services covering consumers' needs, wants and desires, the emotional appeals, information, persuasive tactics and other components of an advertisement must correspond with cultural norms (Akaka \& Alden, 2010).

Customer Acceptance towards Global Product Advertisement: Buying behavior induced by consumer psyche and influenced by social norms. As claimed by Durmaz and Mucahit (2011), cultural components also influence consumer behaviors which the acknowledgment of cultural properties in examining consumer behavior is believed as a crucial variable in marketing activities for instance 
market segmentation, target market, and product positioning. These academicians finally concluded in their research that faith, culture, and tradition are among vital criterion in purchasing goods and services. Keller (2012) states that advertising has played a major role in the psychological evolution of consumers instead of the development of new advanced technology, images shown in the media, changes in modern culture circles and family values. In other words, advertising encourages the interest of desired target markets and demographics. Meanwhile, Calabrese, Capece and Costa (2015) explain that culture values act as coerce that shapes motivations, lifestyles, and product of choices of members' culture. Naseri and Tamam (2012) analyzed that the employment of cues and symbols that reflect cultural values' affiliation to consumers might insensate inducing the information processing ergo develop a favorable emotion. In 2012, De Run et.al has analyses the linkage between language and consumer behavior to understand consumer preferences and acceptance of brands. From the findings disclosed, Chinese consumers in Malaysia earn adversely attitude toward brand and products in the Malay language since the language do not fit this community's language style. They also found to willingly to spent more for Chinese brand as compared to the Malays'. However, the authors suggest that there is more to the perception of Chinese culture rather than language issue concerned because the study revealed that Malaysian Chinese perceive English brand name equally as their native language thus signify the impact of English usage in Malaysia (De Run, Butt, Fam and Jong, 2000).

\section{METHODOLOGY}

The source of primary data is the target respondents consist of 150 respondents. The population chosen is the Muslims residents of Shah Alam area. A quantitative survey was undertaken to serve the purpose of this study. Questionnaires were distributed to a total of 150 respondents. The questionnaires were divided into 5 sections. The first section of the questionnaire required respondents to rate their judgment on the effects of religion on global product advertisement, respectively. The fourth section highlighted items on the consumer acceptance towards global advertising. The following sections require the respondent to rate their judgment on the effects of language and cultural norms on global product advertisement the last section the respondent need to fill up the demographic details. All variables were measured using the 5-point Likert scale. All data were analyzed using Statistical Package for Social Sciences (SPSS).

\section{RESULTS}

In this section, results of the effect between the cultural elements and the customer acceptance towards global product advertisement.

Reliability test were conducted to test the consistency of the answers given by respondent since each independent and dependent variable were measured via Likert scales. As shown in table 4.5, the Cronbach's alpha for all four variables were above 0.60 . The output denotes that language, religion and cultural norms is acceptable at $0.60 \leq \alpha<0.70$ and good at 0.80 for customer acceptance (George and Mallery, 2003). Many sociologists suggest that Cronbach's alpha thumb rule indicates that a value higher than 0.70 explain an adequate reliability (DeVellis, 2003), some are accepting 0.60 as cut off values of Cronbach's alpha. Even though George and Mallery, 2003 states that a value of 0.60 is questionable, Cronbach's alpha value of greater than 0.60 is also considered acceptable. In cases 
INTERNATIONAL JOURNAL OF ACADEMIC RESEARCH IN BUSINESS AND SOCIAL SCIENCES

Vol. 8, No. 11, Nov, 2018, E-ISSN: 2222-6990 @ 2018 HRMARS

that the value of Cronbach's alpha was under 0.60, it is advisable to use Item-Total Statistics to find out items that is necessary to be removed from the measure in order to escalate the inter-item consistency.

Table 1. Reliability Test

\begin{tabular}{lcc}
\multicolumn{3}{c}{ Reliability Statistics } \\
\hline \hline Variable & N of Items & Cronbach's Alpha \\
\hline Religion & 6 & 0.765 \\
Language & 8 & 0.724
\end{tabular}

\begin{tabular}{|c|c|c|c|c|c|}
\hline \multirow[t]{3}{*}{ Table } & \multirow[t]{3}{*}{ Correlation } & Cultural Norms & 6 & 0.639 & \multirow[t]{2}{*}{ Coefficient } \\
\hline & & Customer Acceptance & 7 & 0.886 & \\
\hline & & Religion & Language & $\begin{array}{l}\text { Cultural } \\
\text { Norms }\end{array}$ & $\begin{array}{l}\text { Customer } \\
\text { Acceptance }\end{array}$ \\
\hline $\begin{array}{l}\text { Total } \\
\text { Customer }\end{array}$ & $\begin{array}{l}\text { Pearson } \\
\text { Correlation }\end{array}$ & $.311^{* *}$ & $.599 * *$ & $.558 * *$ & 1 \\
\hline Acceptance & Sig. (2-tailed & .001 & .000 & .000 & \\
\hline & $\mathrm{N}$ & 108 & 108 & 108 & 108 \\
\hline
\end{tabular}

As refer to table 2, explained the results as to meet the objectives of this study. The Pearson correlation results between the variables showed that there are associations between religion, language and cultural norms with customer acceptance towards global product advertisement. Hypotheses were test based on correlation coefficient finding. When there is a correlation between the two variables, it was assumed that the independent variables will have effects on the dependent variable.

H01: The religion effects on customer acceptance towards global product advertisement.

In examining the effect between religion element and customer acceptance towards global product advertisement, this study reveals that there is a medium positive effect (Cohen, 1988) between religion and customer acceptance with a score of $r=.311, p<0.01$. For this reason, the hypothesis is accepted because it is statistically significant.

H02: The language effects on customer acceptance towards global product advertisement.

There is a significant large positive effect between language and customer acceptance, $r=.599$, $p<0.01$ with high levels of language element displays in global ads associate with higher customer acceptance. Findings show that the test is significance and support this presumption hypothesis thus it is generally accepted.

H03: The cultural norms effects on customer acceptance towards global product advertisement. The output from correlation analysis resulting $r=.558, p<0.01$ explains that there is a large correlation effect between these two variables which suggesting a large positive effect between cultural norms element at 55\% contributes to customer acceptance with $99 \%$ confidence level on the result obtained. Due to that, the result validates the third hypothesis and accepts the hypothesis. 


\section{DISCUSSION}

Advertisement with natural language or translation into local language are well perceived by the customer to spark their interest in buying global products. The result stands in the same line with the scholar of thought who believe that language obstacle may generate slower customers' acceptance (De Run, et.al, 2012; Gerritsen, et.al, 2010; Jimenez, et.al, 2013; Keller, 2012). In terms of cultural norms consideration in global advertising, this element is found establish a significant effect with customer acceptance as Malays were judged as the people who embrace its culture well and it is portrayed in their everyday life and how they are doing things (Abdulbaqi and Raji, 2012). Nevertheless, the insertion of cultural norms element in global ads might influence them (Naseri and Tamam, 2012) in this case, their buying decision. Lastly, the findings result disclosed that there are smaller effects of religion element in global ads that mold the customer acceptance. Although the author personally predict that religion element would highly contribute to customer acceptance as religious practice shape peoples' thinking and behavior (Kamarulzaman, Farinda and Madun, 2012) but surprisingly, the result generated explains that the level of customer acceptance is depending on the level of their religiosity (De Run et. al, 2000).

\section{CONCLUSION}

Overall, the result matches the pre-assumption that culture elements cues in global advertising are perceived crucial in influencing customer acceptance towards global product advertising. According to de Run et al. 2012, religion does have effects on customer acceptance towards buying global products because the higher religiosity circles easily get offended by the advertisement of haram or controversial product. These scholars finally conclude that universal application stressed that religion dominates human orientation in relation to life is not appropriate, but religiosity does have an impact towards consumption behavior. Languages will have effects on customer acceptance on global advertisement when what is portrayed about the products catches the customer attention. Language plays an essential role on customer understanding on the global product advertisement and it should reduce misinterpretation about certain product advertisement (Abdulbaqi and Raji, 2012). Cultural norms will have effect on the customer acceptance on advertisement when it matches the needs of customer based on their consumptions (Gunaratne, 2000). So, if the cultural norms match their needs and compatible with the global advertisement offered it will affect their respond towards the advertisement. Other than that, realizing that globalization nowadays has seen the emergence of global consumer culture (Akaka and Alden, 2010), future research might want to investigate the effects especially in terms of the acceptance of global advertising strategy towards consumers in Malaysia so that advertising agency may benefited well from the research.

\section{Acknowledgement}

This research is made possible through the fund provided by Faculty of Business and Management Grant of university Teknologi MARA. 
INTERNATIONAL JOURNAL OF ACADEMIC RESEARCH IN BUSINESS AND SOCIAL SCIENCES

Vol. 8, No. 11, Nov, 2018, E-ISSN: 2222-6990 (C) 2018 HRMARS

\section{Corresponding Author}

Azurin Sani

Universiti Teknologi MARA

Universiti Teknologi MARA, International Business, UiTM Puncak Alam, Faculty of Business and

Management, Bandar Puncak Alam, 43200 Selangor, Malaysia.

Email: Nurzan7884@puncakalam.uitm.edu.my

\section{References}

Abdulbaqi, S.S., \& Raji, R.A. (2012). The Role of Cultural Elements on Advertisement Reception:

Case Study of Malaysians. International Journal on Social Sciences Economics \& Art, Vol.2 (2012) No. 1.

Akaka, M.A., \& Alden, D.L. (2010). Global brand positioning and perceptions: International advertising and global consumer culture. International Journal of Advertising, 29(1), pp. 37-56.

Calabrese, A., Capece, G., Costa, R. \& Pillo, F.D. (2015). Global Market and Commercials: Understanding Cultural Diversities. (online) Available at http://www.wileyonlinelibrary.com

Cohen, J. (1988). Statistical Power Analysis for the Behavioral Sciences (2nd ed.). Hillsdale, NJ: Lawrence Erlbaum Associates, Publishers.

De Run, E.C., Butt, M.M., Fam, K.S., \& Jong, H.Y. (2010). Attitudes towards offensive advertising: Malaysian Muslims' views. Journal of Islamic Marketing, Vol. 1 No. 1, 2010. pp. 25-36.

De Run, E.C., Yee, T.C., \& Khalique, M. (2012). It's not just a brand name: The impact of language on consumer attitude and behavior. International Journal of Research Studies in Management. 2012 October, Volume 1 Number 2, 45-56.

De Vellis, R. F. (2003). Scale Development: Theory and Applications (2nd ed., Vol. 26). Thousand Oaks, CA: Sage Publications.

Gerritsen, M., Nickerson, C., van Hooft, A., van Meurs, F., Korzilius, H., Nederstigt, U., Starren, M., \& Crijns, R. (2010). English in Product Advertisements in Non-English-Speaking Countries in Western Europe: Product Image and Comprehension of the Text. Journal of Global Marketing, 23: 4, 349-365.

George, D., \& Mallery, P. (2003). SPSS for Windows step by step: A simple guide and reference 11.0 update (4th ed.). Boston: Allyn \& Bacon

Gunaratne, A. K., (2000 The Influence of Culture And Product Consumption Purpose On Advertising Effectiveness. ANZMAC 2000 Visionary Marketing for the 21st Century: Facing the Challenge. 443-447. 
INTERNATIONAL JOURNAL OF ACADEMIC RESEARCH IN BUSINESS AND SOCIAL SCIENCES

Vol. 8, No. 11, Nov, 2018, E-ISSN: 2222-6990 @ 2018 HRMARS

Jimenez, F.R., Hadjimarcou, J., Barua, M.E., \& Michie, D.A. (2013). A cross-national and cross generational study of consumer acculturation to advertising appeals. International Marketing Review, Vol. 30 No. 5, 2013 pp.418-439

Kamarulzaman, Y., Farinda, A.G., \& Madun, A. (2012). The Acceptance of Islamic Hotel Concept in Malaysia: A Conceptual Paper. Conference Paper. P. 1-10.

Kotabe, M., \& Helsen, K. (2010). Global Marketing Management-5th ed. NJ: John Wiley \& Sons, Inc.

Keller, K. (2012). Advertising and Consumerism in the Food Industry, Honors Thesis, Johnson Wales University.

Malaysian Communications and Multimedia Commission (SKMM), (2009). Advertising Development in Malaysia: Catching Eyeballs in Changing Media. P. 3-44.

Naseri, A., \& Tamam, E. (2012). Impact of Islamic Religious Symbol in Producing Favorable Attitude Toward Advertisement. The Public Administration and Social Policies Review, IV Year, No. 1 (8) / June 2012.

Nwagbara, G.U., \& Umor, E.F. (2012). The Impact of Nigerian Cultural Elements on the Design of Print Media Ads. J Communication, 3(2): 59-66.

Schnalke, M., \& Mason, R.B. (2014). The influence of culture on marketing communications: critical cultural factors influencing South African and German businesses. Problems and Perspectives in Management, Volume 12, Issue 1, 2014.

Yalcin, E., \& Cimendag, I., (2012). Global marketing advertising with cultural differences, Master's Thesis, Jönköping University. 